\title{
STYRENE MALEIC ANHYDRIDE COPOLYMERIZATION IN A RECYCLE TUBULAR REACTOR: REACTOR STABILITY AND PRODUCT QUALITY
}

\author{
SAHBI BELKHIRIA, THIERRY MEYER and ALBERT RENKEN* \\ Institut de Génie Chimique, Ecole Polytechnique Fédérale, CH-1015 Lausanne, Switzerland
}

(Received 11 May 1994; accepted for publication 27 September 1994)

\begin{abstract}
Styrene maleic anhydride copolymers (SMACs) are of particular commercial and academic interest. The bulk copolymerization reaction is characterized by a very fast reaction rate and an important gel effect. The copolymer has a strong tendency to be alternate when maleic anhydride is in excess. In order to obtain a copolymer with less than $50 \%$ of incorporated MA, a good quality of mixing must be reached. As a matter of fact, the copolymer composition is particularly sensitive to local concentration and temperature fluctuations. For this purpose a tubular recycle reactor was developed to ensure good homogeneity of concentration and temperature. The composition of the copolymer obtained is in good agreement with predicted values and the uniformity of composition was measured for the entire molecular mass distribution. The characterization of the reactor (both hydrodynamic and stability) and the quality of the resulting polymer are presented herein. The limits of use of this reactor for the ST/MA copolymerization are described. Furthermore the effects of the operating parameters on the reactor and the copolymerization reaction are discussed.
\end{abstract}

\section{INTRODUCTION}

Styrene maleic anhydride copolymers (SMACs) were commercially introduced in the production of watersoluble resins, possessing high functionality, low solution viscosity, and water insensitivity upon drying. They are widely employed in surface treatments (floor polishes, pigment dispersants, paper sizing, and coatings for metals) and in the automotive industry (glass reinforced polymers). The copolymerization between styrene (ST) and maleic anhydride (MA), is a very fast and exothermic reaction $\left(\Delta H_{r}=-81 \mathrm{~kJ} /\right.$ mol). Efficient heat and mass transfer is indispensable to avoid severe hot spots, reactor runaway and consequently poor copolymer quality. The copolymerization is characterized by a strong tendency to form 1:1 equimolar copolymer unless MA concentration is held at an extremely low level during the cntirc polymerization sequence. In this case, SMAC with an excess of ST in its composition is produced. However, this kind of copolymer (random SMAC) is experimentally difficult to obtain due to competition of ST homopolymerization. Therefore, semibatch or open mixed reactors (continuously operated perfectly mixed reactors), such as recycle tubular reactors, become attractive for production of both equimolar and random SMAC, since they operate at constant monomer composition and avoid local concentration gradients. For equimolar SMAC production in our pilot plant, the polymerization is carried out in the presence of excess of MA in the reaction mixture. No additional solvent is used. For random

\footnotetext{
To whom correspondence should be addressed
}

SMAC production, a large excess of styrene is necessary. In that case, small amounts (up to vol\%) of solvent may be introduced.

\section{COPOLYMERIZATION KINETICS}

The rates of ST/MA copolymerization are high compared to the homopolymerization of styrene. Kinetic data are obtained using a differential scanning calorimeter (DSC). A typical result is shown in Fig. 1, where specific heat production is plotted against reaction time for different initial molar fractions of MA $\left(f_{2,0}=n_{2,0} /\left(n_{1,0}+n_{2,0}\right)\right)$. At higher MA concentrations $\left(f_{2,0}>0.3\right)$, the polymerization is characterized by a strong gel effect, with maximum heat production observed at ca. $50 \%$ monomer conversion. The maximum reaction rate depends strongly on the initial monomer composition. This is shown in Fig. 2, where experimentally observed maximum polymerization rates as a function of the initial molar fraction of $M A$ are given. Up to $f_{2,0}=0.3$, the rate increases nearly linearly with the initial MA concentration. Then a very steep increase is observed reaching a maximum at $f_{2,0}=0.6$. At higher concentrations, the excess MA acts as a solvent, and the reaction rate decreases with higher dilution.

Due to the strong effect of MA on the polymerization rate it is not possible to describe the kinetics in the whole concentration range with a unique kinetic model. At MA concentrations up to $f_{2,0}=0.3$, the empirical model proposed by Hui and Hamielec (1972) can be applied (Belkhiria et al., 1994). At 


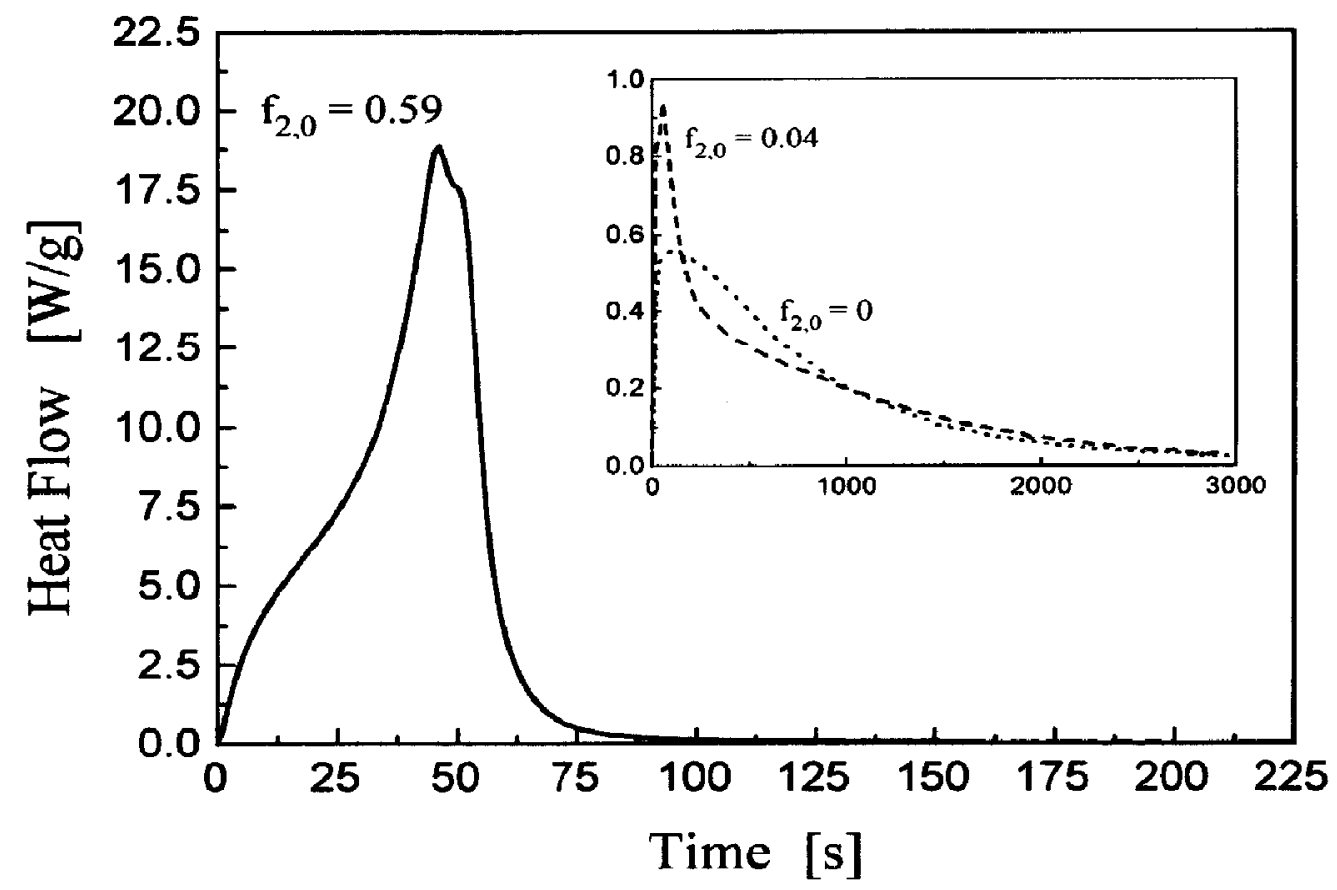

Fig. 1. Reaction rate of ST/MA copolymerization with different initial MA concentrations, $T=140^{\circ} \mathrm{C}$.

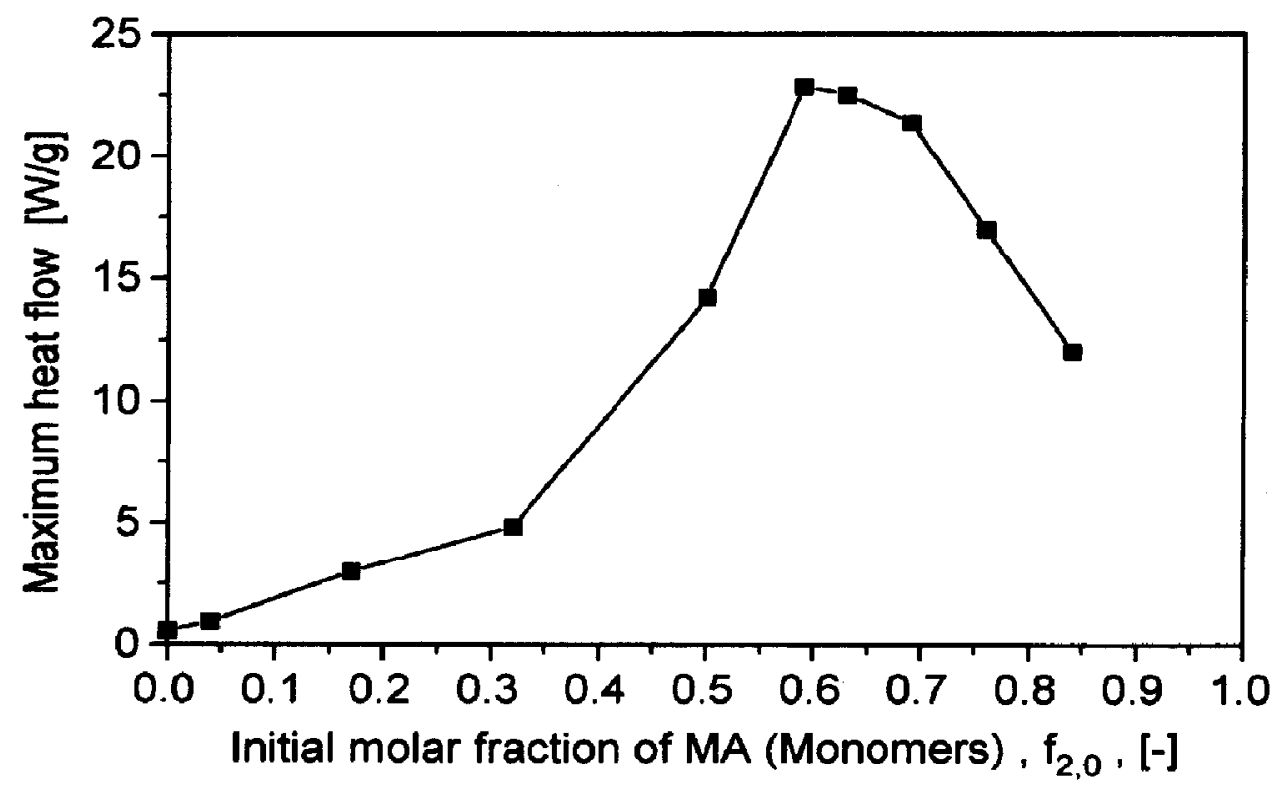

Fig. 2. Maximum heat production (reaction time) as a function of initial $\mathrm{MA}$ concentrations, $T=140^{\circ} \mathrm{C}$.

higher concentrations, $\left(0.5<f_{2,0}<0.8\right)$ a modified diffusion model (Fleury et al., 1992) is used to describe the strong rate acceleration with monomer conversion. The copolymerization reactions can be represented by the following scheme (Trivedi and Culbertson, 1982): 
<smiles>C=Cc1ccccc1</smiles><smiles>CC1C=CC(=O)O1</smiles><smiles>C=Cc1ccccc1</smiles><smiles>CC1=C(C)C(=O)OC1=O</smiles>

$$
\begin{aligned}
& \operatorname{mMM} M_{1}+M_{1} \stackrel{k_{11}}{\longrightarrow} \operatorname{Mm} M_{1} M_{1}^{\prime} \\
& M M_{1}^{\prime}+M_{2} \stackrel{k_{12}}{=} \mathscr{M M} M_{1} M_{2}^{\prime} \\
& \operatorname{MNM} \mathrm{M}_{2}^{\prime}+\mathrm{M}_{1} \stackrel{k_{21}}{\longrightarrow} \operatorname{Mm} \mathrm{M}_{2} \mathrm{M}_{1}^{\prime} \\
& \mathscr{M M} \mathrm{M}_{2}^{\prime}+\mathrm{M}_{2} \stackrel{k_{22}}{\longrightarrow} \mathrm{WMM}_{2} \mathrm{M}_{2}^{\prime}
\end{aligned}
$$

$r_{1}=\frac{k_{11}}{k_{12}} ; \quad 0.01<r_{1}<0.13 \quad r_{2}=\frac{k_{22}}{k_{21}} ; \quad r_{2}=0$

The instantaneous copolymerization composition depends on the reactivity ratios $r_{1}$ and $r_{2}$ and the composition of the monomer mixture, as defined in eq. (1).

$$
1-F_{2}=F_{1}=\frac{r_{1} f_{1}^{2}+f_{1} f_{2}}{r_{1} f_{1}^{2}+2 f_{1} f_{2}+r_{2} f_{2}^{2}} ; \quad f_{2}=1-f_{1}
$$

The molar fraction of MA in the polymer $\left(F_{2}\right)$ as a function of the monomer composition is given in Fig. 3 for the extreme values of reactivity ratios found in literature. For monomer concentrations higher than $f_{2}>0.5$ the polymer composition is nearly constant at $F_{2}=0.5$. At low MA concentrations $\left(f_{2} \leq 0.3\right)$ the polymer composition is very sensitive to small local concentration fluctuations in the reactor.

\section{PILOT PLANT DESCRIPTION AND HYDRODYNAMIC BEHAVIOR}

Previous work (Nguyen et al., 1985) with an industrial partner (Sulzer) led to the development of a pilot plant, composed of a recycle tubular reactor (RTR) followed by a tubular reactor (TR), completely filled with static mixers. The system efficiency had already been demonstrated for the bulk polymerization of styrene (Meyer and Renken, 1990) and the polymerization of methyl

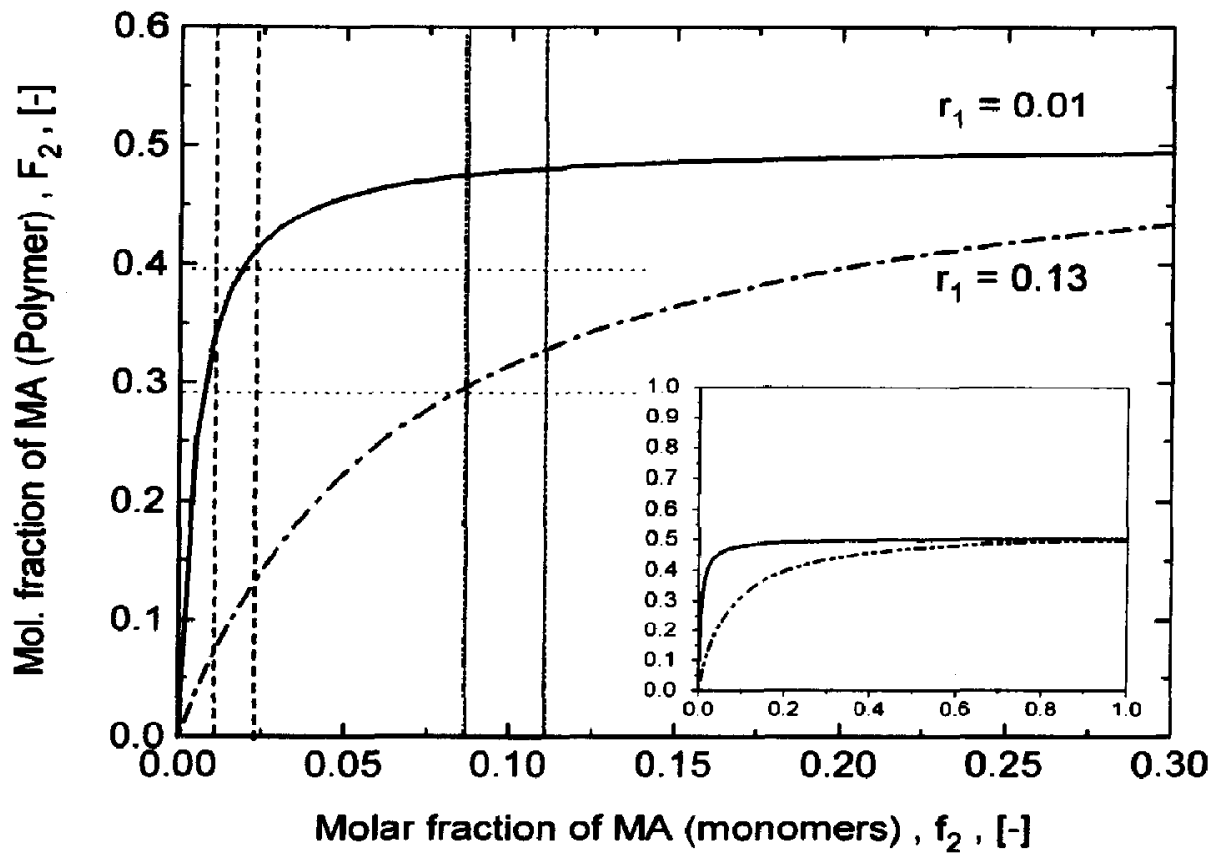

Fig. 3. Estimated SMAC composition. 


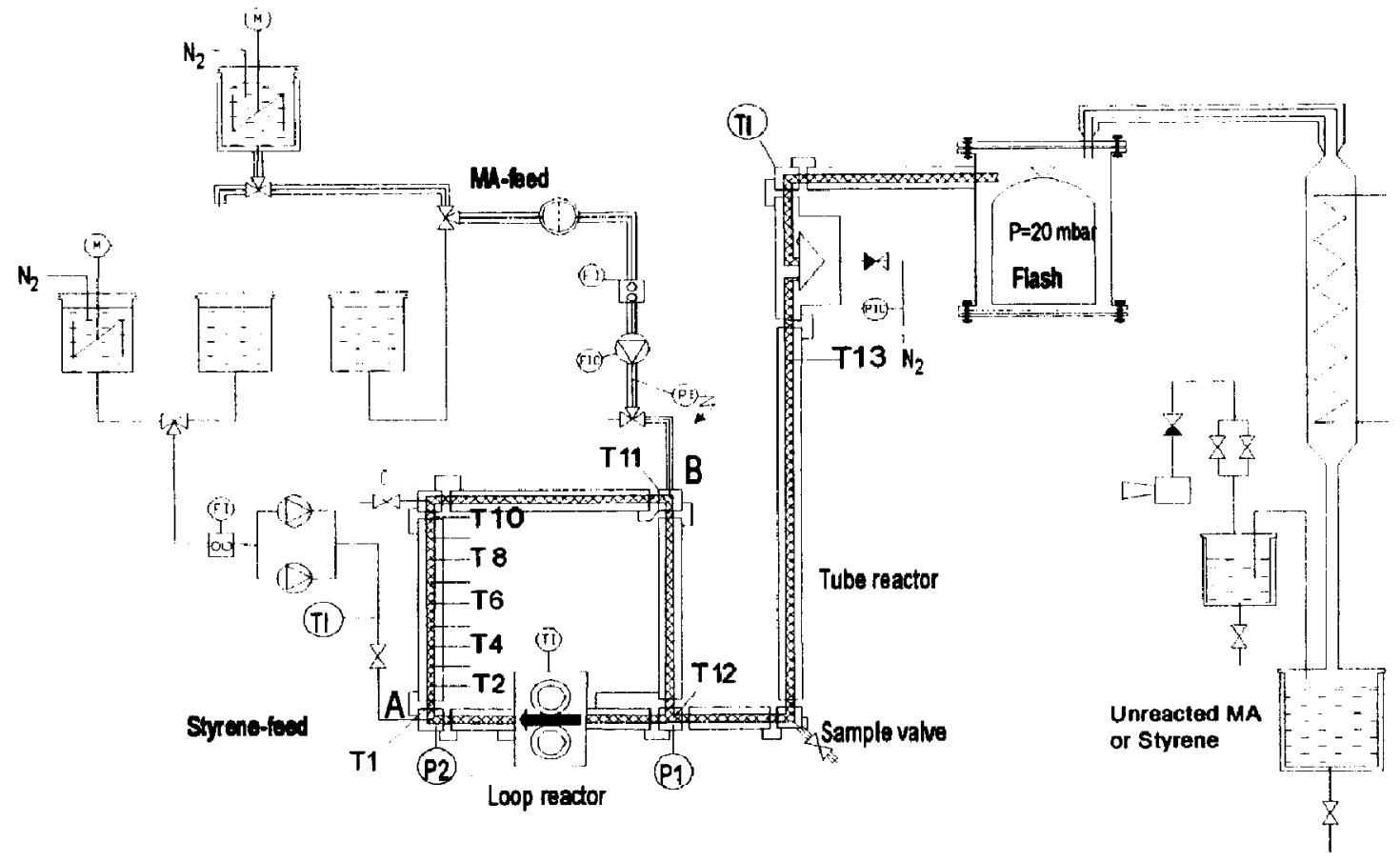

Fig. 4. Pilot plant reactor.

methacrylate at high temperature (Fleury et al., 1992). The pilot plant was modified and adapted for the copolymerization as presented in Fig. 4 . Due to the high reaction rate and exothermicity of the present copolymerization, the reactor must ensure rapid mass and thermal mixing, and be able to remove up to $1 \mathrm{MW} / \mathrm{m}^{3}$ of heat production. Except for the condenser in the flash separation stage constructed with Pyrex glass, all parts of the reactor consist of 316 stainless steel. The RTR is filled with Sulzer SMX mixers (vertical tubes) in order to enhance mixing efficiency where the reaction rate is high, and with SMXL mixers (horizontal tubes) in the remaining parts. All parts have $200 \mathrm{~mm}$ inner diameter and $500 \mathrm{~mm}$ length. The post-tubular reactor is packed with SMXL mixers to a total length of $1,500 \mathrm{~mm}$. The SMX mixer provides better mixing efficiency but leads to higher pressure drop compared to the SMXL. At point A (Fig. 4), styrene monomer is injected. Due to its high concentration the polymerization rate is maximal in the tube located just after the injection point, leading eventually to hot spots. Therefore the temperature profile in this part of the reactor is measured with 10 thermocouples ( $T 1$ to $T 10$ ). As mixing efficiency is crucial for the product quality, a specially designed intensive mixing device is added at point $\mathrm{A}$ (Fig. 5). Several devices having inner diameter $6-20 \mathrm{~mm}$ and filled with Sulzer SMX mixers were used. The optimum practical value was found to be $15 \mathrm{~mm}$.
Smaller diameters lead to unacceptably high pressure drops in the reactor.

The hydrodynamic behavior of the RTR and the residence time distribution (RTD) were studied by introducing a colored die in form of a pulse. The response was measured at the outlet of the loop reactor. A typical result is represented in Fig. 6. The residence time distribution of the loop reactor is characterized by the mean residence time $(\tau)$, the circulation time $\left(\tau_{r}\right)$, the recycle ratio $(\varphi)$, and the axial dispersion in the tube. The dispersion is characterized by the Bodenstein number defined as

$$
B o=\frac{u L}{D_{\mathrm{ax}}}=\frac{L^{2}}{\tau_{r} D_{\mathrm{ax}}}
$$

Warnecke et al. (1985) proposed a relatively simple model to describe the RTD in a tubular loop reactor:

$$
E(t) \cong a_{\mathrm{o}} \exp \left(s_{\mathrm{o}} t\right)+2 \rho_{1} \exp \left(-x_{1} t\right) \cos \left(y_{1} t+\theta_{1}\right)
$$

$\rho_{1}$ is a constant depending on tracer concentration and $\theta_{1}$ the phase shift. The other model parameters can be related to the following main system parameters:

$\tau=-1 / s_{\mathrm{o}}$ mean residence time in the reactor

$\tau_{r}=2 \pi / y_{1}$ mean circulation time

$r=\varphi /(\varphi+1)=\exp \left(s_{o} T_{r}\right)$

recycle index, $\varphi=$ recycle ratio 


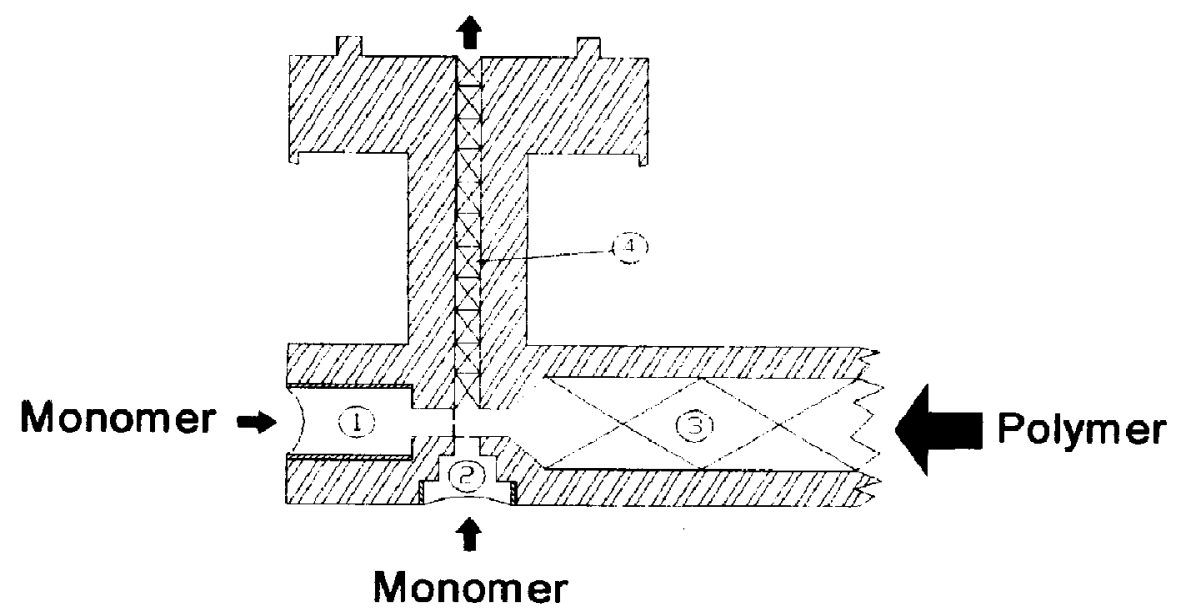

Fig. 5. Mixing device implemented at injection point $\mathbf{A}$.

$$
\sigma_{r}^{2}=\left(x_{1}+s_{0}\right) \tau_{r}^{3} / 2 \pi^{2}
$$

variance of the tracer within a cycle

$a_{0}, s_{0}, x_{1}$ and $y_{1}$ can be estimated from the experimental RTD curve. As the second term in eq. (4) has a much faster decay than the first one, we obtain for large values of $t$ :

$$
E(t) \cong a_{\mathrm{o}} \exp \left(s_{\mathrm{o}} t\right)
$$

Therefore $a_{o}$ and $s_{o}$ are estimated from the non-oscillating part of the RTD curve. If $t_{1}<t_{2}, e_{1}=E\left(t_{1}\right)$ and $e_{2}=E\left(t_{2}\right)$ then (Fig. 6):

$$
s_{0}=\left(t_{2}-t_{1}\right)^{-1} \ln \left(e_{2} / e_{1}\right)
$$

The circulation time $\tau_{r}$ is approximately equal to the period of oscillations in the residence time distribution $E(t)$, and therefore can be estimated from the distance of two successive maxima (Fig. 6). At these points, $\cos \left(y_{1} t+\theta_{1}\right)=1$ and $x_{1}$ is estimated by eq. (11):

$$
x_{1}=1 / \tau_{r} \ln \left(h_{3} / h_{4}\right)
$$

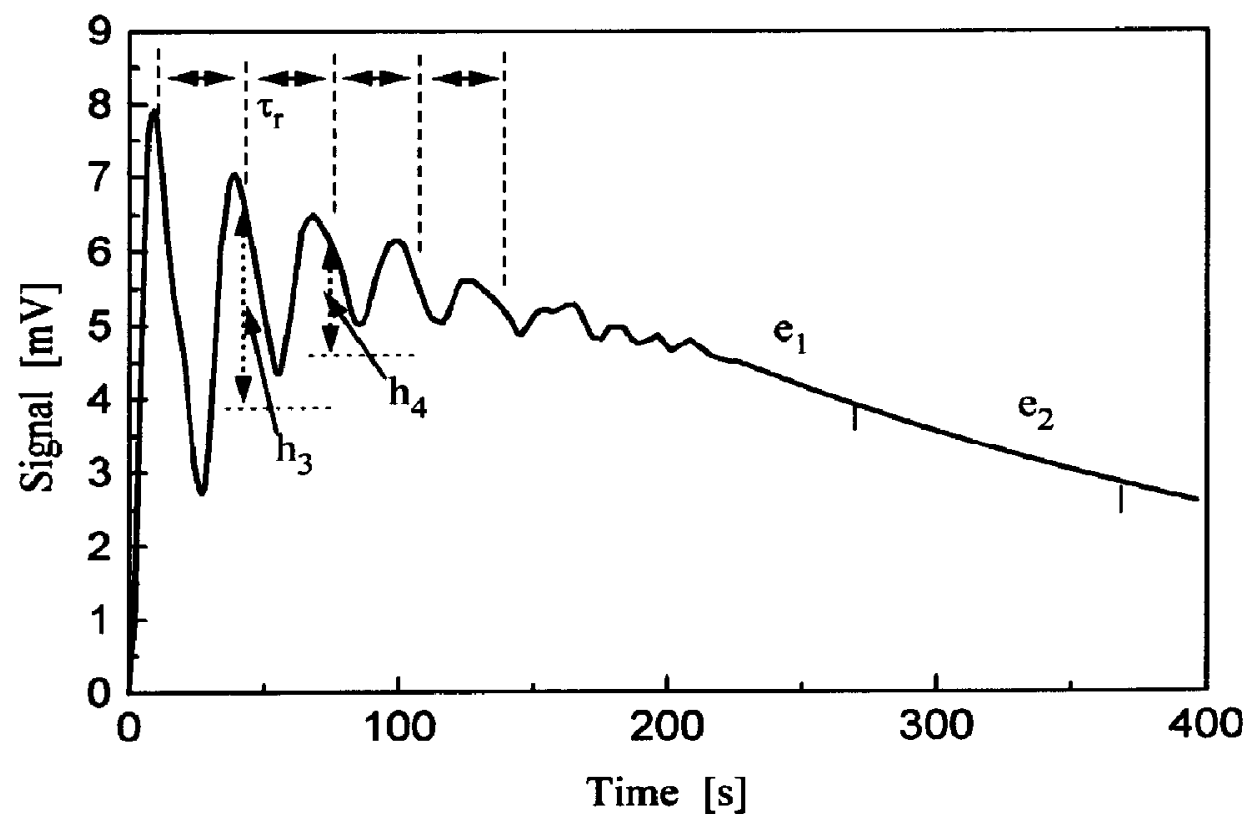

Fig. 6. Experimenal RTD measurements during polymerization in the RTR, $Q=122 \mathrm{~mL} / \mathrm{min}, \tau=4.5 \mathrm{~min}, \varphi=9.3$, $T=200^{\circ} \mathrm{C}, f_{2,0}=0.72, X_{1}>95 \%$. 
Finally the Bodenstein number defined for one cycle can be estimated by

$$
B o=2 \tau_{r}^{2} / \sigma_{r}^{2}
$$

Although the oscillating part of the experimental RTD curve was not as expected (an ideal response to an ideal pulse injection should give a higher amplitude), the obtained experimental parameters $\left(\tau, \tau_{r}\right.$ and $\left.\varphi\right)$ were very close to those calculated from the reactor volume, reactant feed and the pumping rate of the gear pump. As the parameters do not vary with operation time, it can be concluded that under experimental conditions there occurs no rouling by polymer sticking onto the tube wall. Due to the high recycle ratio, $\varphi$, the macroscopic behavior of the RTR is very close to a continuous stirred tank reactor. The estimated dispersion in the tubes characterized by the Bodenstein number per meter, is close to values determined by Flaschel et al. (1985) from residence time distributions in a tubular reactor filled with static mixers. The high value of $B o / L=100 \mathrm{~m}^{-1}$ allows us to consider plug flow behavior in the tubes. Measured and theoretically predicted values for the different hydrodynamic parameters are summarized in Table 1.

\section{REACTOR STABILITY}

As shown in Fig. 2, the maximum reaction rate is observed for initial MA fractions between $0.5<f_{2,0}<0.7$. Figure 7 shows that under these conditions, styrene conversion, in an ideally mixed open reactor, attains $90 \%$ for a space time of about $40 \mathrm{~s}$. Reactor simulations shown in this figure predict an unacceptably high parametric sensitivity for conversions of $20-80 \%$. The heat production in this domain can reach up to $8 \mathrm{MW} / \mathrm{m}^{3}$, which cannot be evacuated from the reactor. In that case, and for the present reactor with $\varphi \cong 20$, the mean temperature difference between the reacting mixture and the wall is estimated to be $\Delta T=\bar{T}-T_{w}>160^{\circ} \mathrm{C}$. To avoid these problems, copolymerization must be carried out at space timcs in the ordcr of $10 \mathrm{~min}$, leading to a styrene conversion higher than $99 \%$. Thus, the overall heat production, estimated to be $0.5-1.0 \mathrm{MW} / \mathrm{m}^{3}$, can be evacuated without any problem. However, the local heat production may exceed these values and lead to axial temperature profiles as shown in Fig. 8 for two recycle ratios. At value of $\varphi \cong 10$, the maximum axial temperature profile in the loop $\left(\Delta T_{\max }\right)$ was found to be $12^{\circ} \mathrm{C}$. For a higher recycle ratio $(\varphi \geq 20)$, the $\Delta T_{\max }$ is smaller and does not exceed $4^{\circ} \mathrm{C}$ for our experimental conditions. The recycle ratio in the loop reactor is limited by the viscosity of the reaction mixture leading to high pressure drops. Therefore, the excess of MA and the reaction temperature must be chosen so as not to exceed a pressure drop $(\Delta p)$ of ca. 60 bar.

For inlet concentrations containing a large excess of ST (random SMAC production), the presence of small amounts of the solvent, methyl ethyl ketone (MEK) is necessary to prevent reactor fouling. Therefore 1-5 vol\% of MEK is added to the feed during polymerization. The reaction is thus carried out without any reactor stability problem. If no solvent is introduced, a progressive polymer deposition on the tube wall occurs (Fig. 9), especially at the injection points (A and B) and at the outlet of the RTR. Temperature and heat transfer decrease at these points and progressive plugging of the reactor occurs. The consequence is the shut-down of the reactor followed by a cleaning procedure.

\section{PRODUCT QUALITY}

Mixing efficiency in the reactor was optimized in order to minimize local concentration and temperature gradients. For the experimental conditions used, according to Belkhiria et al. (1994), the energy dissipated allows us to obtain a segregation index of 4 $6 \%$, indicating that only a small part of the fluid is not perfectly micromixed.

In the reactor, copolymerization was performed in a way to minimize solvent concentrations and to avoid initiators. The influence of experimental parameters such as space time, recycle ratio, inlet monomer composition and wall temperature on the molecular weight distribution and the copolymer composition were studied. It is observed that increasing temperature decreases the mean molecular mass and pressure drop (Table 2). In order to decrease the initial $\mathrm{MA}$ inlet concentration from $f_{2,0}=0.720 .63$, the temperature must be raised to overcome viscosity problems. This has an effect on the mean molecular mass and the polydispersity, both of which increase (yielding more polydispersed polymer).

Two series of experiments were performed. One in excess of MA (series I) and one at low contents of initial MA (series II). The results are quite different. For series I an alternate copolymer is produced and high viscosity is reached leading to a pressure drop up to 60 bars. In the second case, styrene is in excess, and a random copolymer is obtained with higher molecular mass. The pressure drop in the reactor is lower due to slower reaction rates leading to incomplete

Table 1. Comparison between experimental and predicted values (MA in excess)

\begin{tabular}{|c|c|c|c|c|c|c|c|c|c|}
\hline \multirow[t]{2}{*}{$\mu$ (Pa s) } & \multicolumn{2}{|c|}{$\tau_{r}(s)$} & \multicolumn{2}{|c|}{$\tau(\min )$} & \multicolumn{2}{|c|}{$r$} & \multicolumn{2}{|c|}{$\varphi$} & \multirow{2}{*}{$\begin{array}{l}\text { Bo/L }\left(\mathrm{m}^{-1}\right) \\
\exp .\end{array}$} \\
\hline & theor. & exp. & theor. & exp. & theor. & $\exp$ & theor. & exp. & \\
\hline $\begin{array}{l}0.3 \\
9\end{array}$ & $\begin{array}{l}41 \\
27\end{array}$ & $\begin{array}{l}42 \\
29\end{array}$ & $\begin{array}{c}11 \\
4.5\end{array}$ & $\begin{array}{r}11.5 \\
5.2\end{array}$ & $\begin{array}{l}0.94 \\
0.90\end{array}$ & $\begin{array}{l}0.94 \\
0.91\end{array}$ & $\begin{array}{c}15 \\
9.3\end{array}$ & $\begin{array}{l}16 \\
10.3\end{array}$ & $\begin{array}{r}91 \pm 10 \\
105 \pm 12\end{array}$ \\
\hline
\end{tabular}




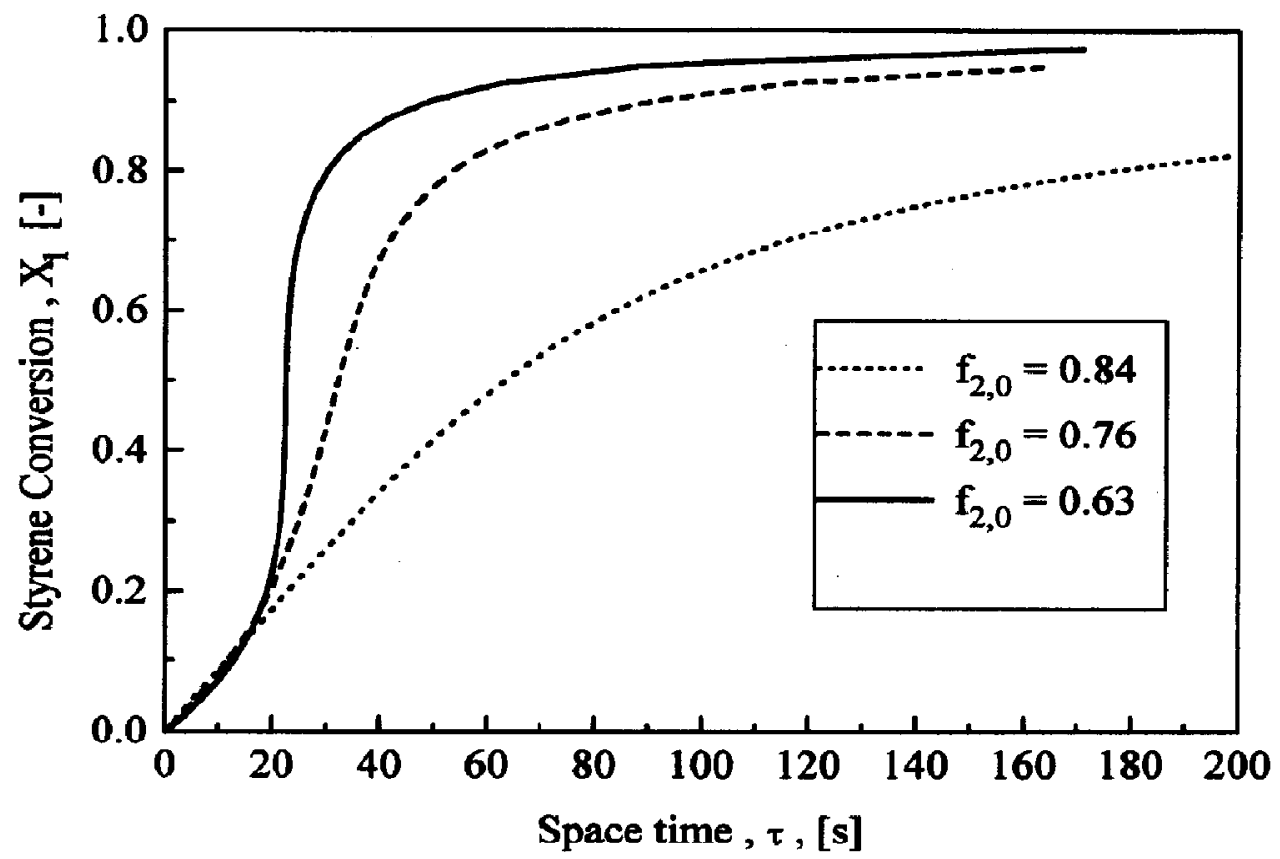

Fig. 7. Styrene conversion vs. space time for different MA initial molar fractions. Simulation results for an open mixed reactor, $T=140^{\circ} \mathrm{C}$.

Table 2. Experimental conditions and results for RTR, $\tau=11 \mathrm{~min}, \varphi=22, X_{1} \cong 0.99, \Delta T_{\max } \leq 4^{\circ} \mathrm{C}$

\begin{tabular}{llllll}
\hline$f_{2,0}$ & $\bar{T}\left({ }^{\circ} \mathrm{C}\right)$ & $\Delta T\left({ }^{\circ} \mathrm{C}\right)$ & $\Delta p($ bar $)$ & $\bar{M}_{n}(\mathrm{~g} / \mathrm{mol})$ & $D$ \\
\hline 0.72 & 185 & 20 & 22 & 22,800 & 1.6 \\
0.72 & 200 & 40 & 60 & 16,400 & 1.9 \\
0.63 & 215 & 45 & 23 & 18,750 & 2.2 \\
0.63 & 230 & & 13,100 & 2.4 & \\
\hline
\end{tabular}

Table 3. Experimental conditions and results for RTR

\begin{tabular}{llllllllll}
\hline Series & $f_{2,0}$ & $T\left({ }^{\circ} \mathrm{C}\right)$ & $\tau(\mathrm{min})$ & $\varphi$ & $\bar{M}_{n}(\mathrm{~kg} / \mathrm{mol})$ & $D$ & $F_{2}$ & $\Delta p(\mathrm{bar})$ & $X_{1}(\%)$ \\
\hline I & $0.63-0.75$ & $185-230$ & $4.5-15$ & $y \ldots 22$ & $13-25$ & $1.5-2.5$ & 0.5 & $2-60$ & $80-99$ \\
II & $0.04-0.15$ & $115-145$ & $11-18$ & $20-32$ & $47-132$ & $2.2-3.3$ & $0.3-0.4$ & $0-1$ & $40-60$ \\
\hline
\end{tabular}

conversion. A summary of the experimental conditions and results is presented in Table $3 . F_{2}$ represents the molar fraction of MA units in the copolymer.

The overall copolymer composition was measured by titration of acid groups in the polymer. In order to assess the instantaneous copolymer composition as a function of the molecular weight distribution, a double wavelength UV detection is coupled with a GPC chromatograph. The two wavelengths were set to $260 \mathrm{~nm}$, corresponding to the maximum absorbance of the styrene group and $230 \mathrm{~nm}$ for the MA group.

In Fig. 10, $A$ and $B$ are two examples of random SMAC copolymers produced with the same initial monomer composition $\left(f_{2}=0.04\right)$, but under different experimental conditions. Except for the flanks of the distribution where errors are high due to the low signal, good composition homogeneity was obtained. No polystyrene homopolymer was produced, which was confirmed by solubility tests.

\section{CONCLUSIONS}

Depending on the monomer in excess, the stable and safe operating conditions of the reactor may change. For series I (MA in excess, $0.6<f_{2,0}<0.8$ ), the recycle ratio must be maintained above 20 , and the mean reaction temperature must be at least of $180^{\circ} \mathrm{C}$. Below this temperature the viscosity becomes too high, and the behavior of the reactor is no longer stable. However, it is preferable to work at initial MA molar fractions $f_{2,0}$ higher than 0.7 to get sufficient 


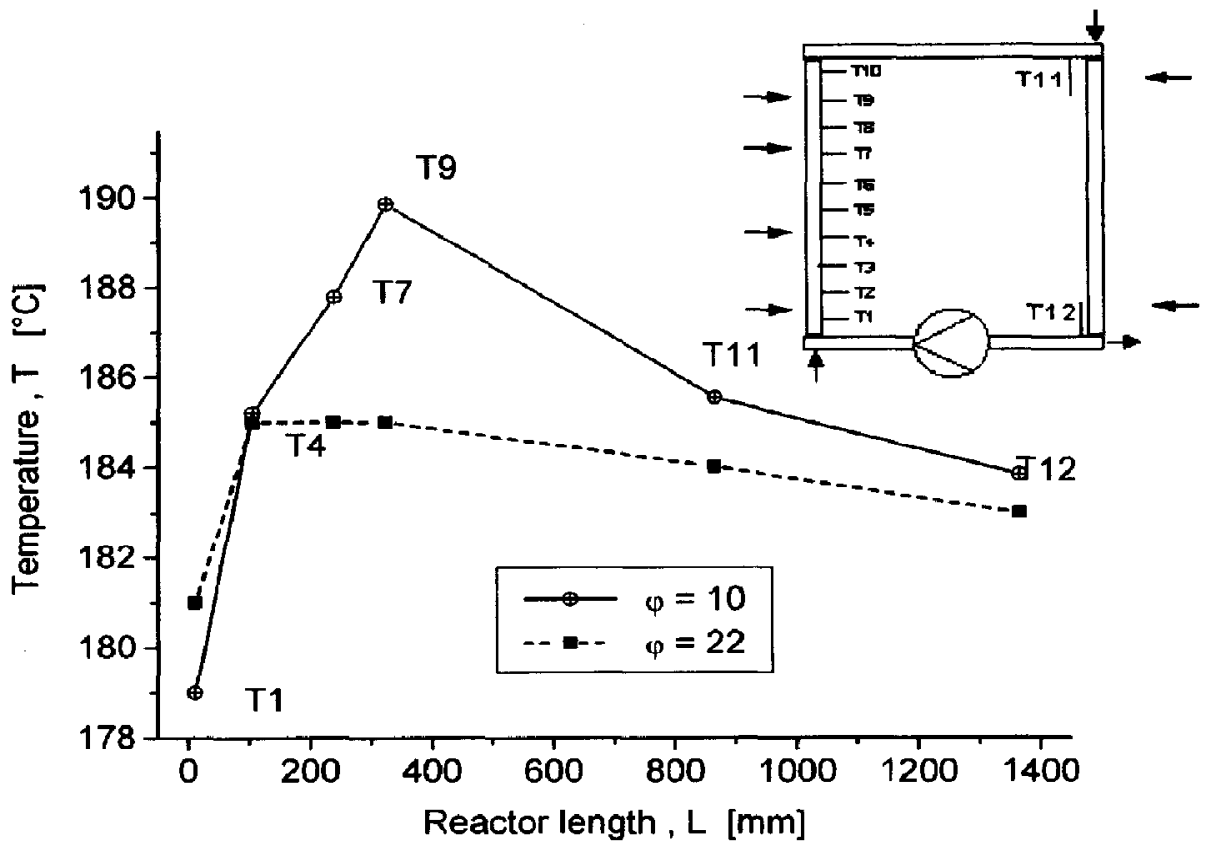

Fig. 8. Axial temperature profile in the RTR, $f_{2,0}=0.72, T_{w}=180^{\circ} \mathrm{C}, \tau=11 \mathrm{~min}$.

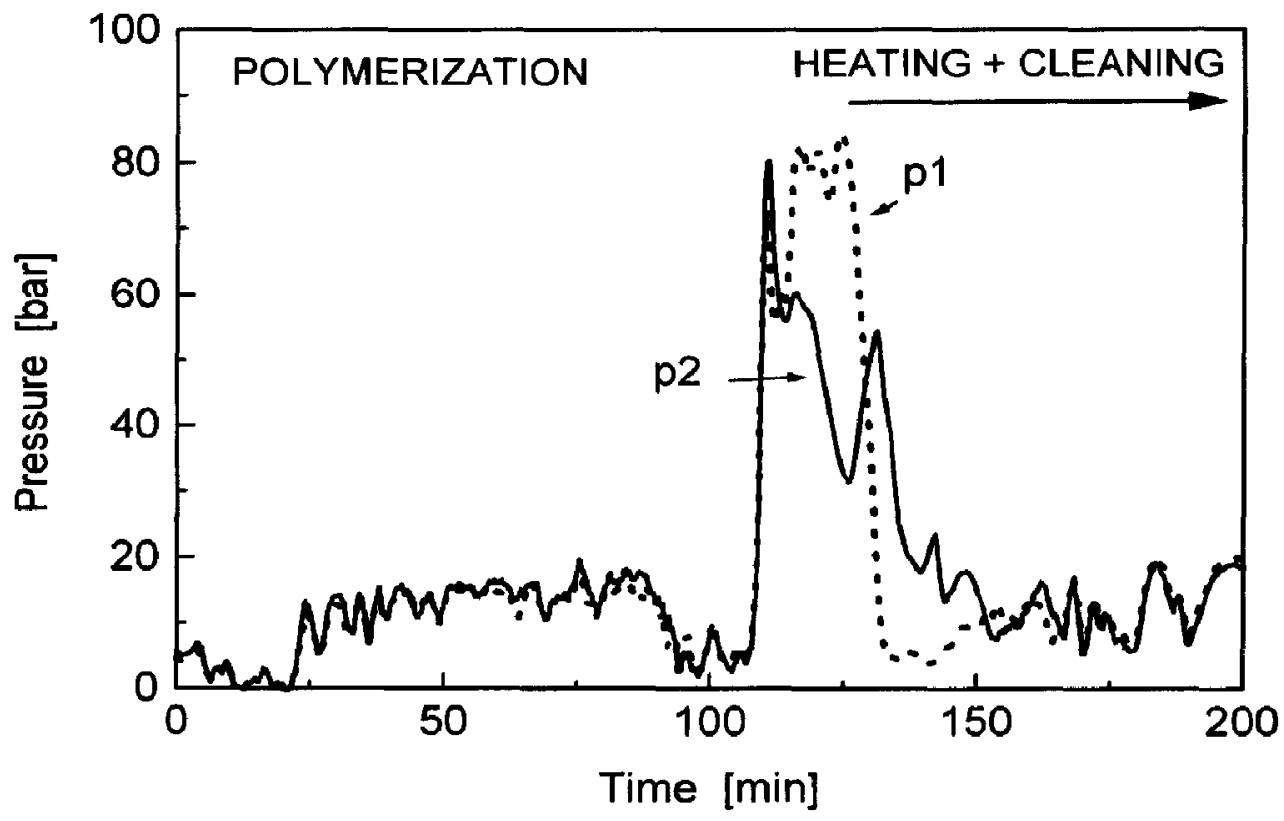

Fig. 9. Pressure profile in the RTR. No solvent, $f_{2,0}=0.15, T_{w^{\prime}}=135^{\circ} \mathrm{C}, \varphi=30$. 


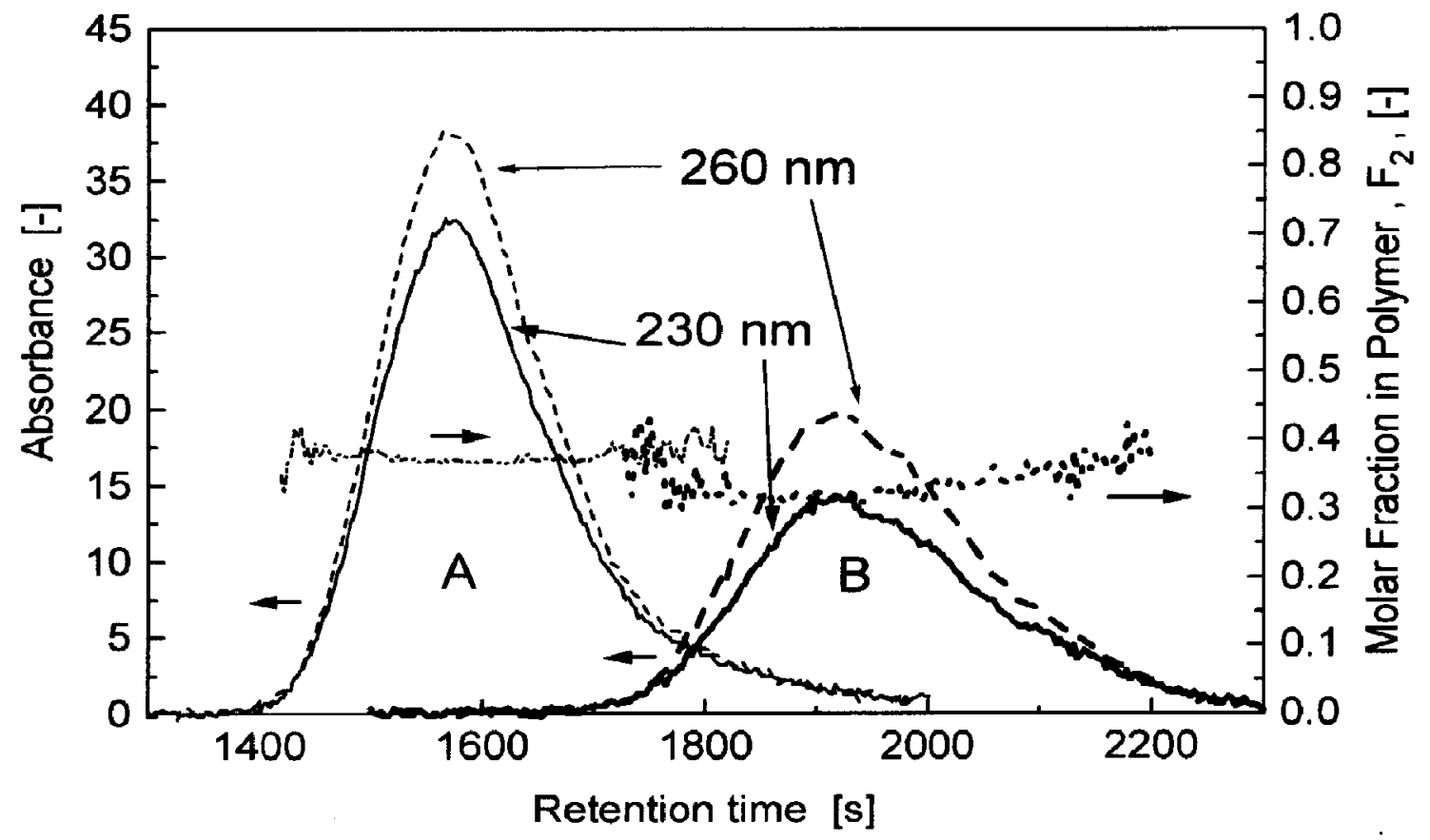

Fig. 10. Composition homogeneity of two random SMACs, $f_{2,0}=0.04, \varphi=20 . \quad \mathrm{A}: \quad \hat{T}=128^{\circ} \mathrm{C}, \tau=12.5 \mathrm{~min}$, $[\mathrm{MEK}]=1 \mathrm{vol} \% . \mathrm{B}: \bar{T}=115^{\circ} \mathrm{C}, \tau=11.0 \mathrm{~min},[\mathrm{MEK}]=5 \mathrm{vol} \%$.

micromixing efficiency and satisfactory product quality. For $f_{2,0}<0.7$ the mean temperature has to be raised to values above $200^{\circ} \mathrm{C}$. For series II (styrene in excess), $f_{2,0}<0.15$ and temperature below $150^{\circ} \mathrm{C}$, a small amount of solvent (MEK) is needed and the recycle ratio must be higher than 25 in order to ensure good micromixing. In both series, the copolymer composition obtained is in good agreement with expected values calculated from the reactivity ratios of the two comonomers (Fig. 3).

Acknowledgements-Financial support of the Commision pour l'Encouragement de la Recherche Scientifique the Van Baerle (Switzerland) and Sulzer (Switzerland) companies, is gratefully acknowledged.

\section{NOTATION}

Bo Bodenstein number, -

$D$ polydispersity index, -

$\Delta H_{r} \quad$ reaction enthalpy, $\mathrm{kJ} / \mathrm{mol}$

$\Delta p \quad$ pressure drop, bar

$\Delta T$ mean temperature difference between reacting mixture and wall, ${ }^{\circ} \mathrm{C}$

$\Delta T_{\max }$ maximal axial temperature profile in the reactor, ${ }^{\circ} \mathrm{C}$

$f_{i} \quad$ instantaneous molar fraction of monomer $i$ in

comonomer mixture, -

$f_{2,0} \quad$ initial molar fraction of $\mathrm{MA}$,
$F_{i} \quad$ instantaneous molar fraction of monomer $i$ in the copolymer, -

$L \quad$ length, $m$

$\bar{M}_{n} \quad$ mean molecular mass in number, $\mathrm{kg} / \mathrm{mol}$

$n_{i} \quad$ amount of reactant $i, \mathrm{~mol}$

$p \quad$ pressure, bar

$r_{1}, r_{2}$ redclivily ratio, -

$t$ time, s

$T$ temperature, ${ }^{\circ} \mathrm{C}$

$\bar{T}$ mean temperature in the loop reactor, ${ }^{\circ} \mathrm{C}$

$X$ conversion, -

\section{Greek symbols}

$\varphi$ recycle ratio, -

$\sigma_{r}^{2} \quad$ variance, $\mathrm{s}^{2}$

$\tau \quad$ space time, $s$

$\tau_{r} \quad$ circulation time, $s$

$\rho_{1}$ constant depending on tracer concentration,

$\theta_{1} \quad$ phase shift,

\section{Subscripts}

0 initial

1 styrene

2 maleic anhydride

$\boldsymbol{W}$ wall 


\section{REFERENCES}

Belkhiria, S., Meyer, T. and Renken, A., 1994, Study of micromixing in polymerization reactions and its application in experimental copolymerization. AIChE Symp. Ser. 90, $117-122$.

Flaschel, E., Nguyen, K. T. and Renken, A., 1985, Improvement of homogeneous tubular reactors operated at low Reynolds number, in Proceedings of the 5 th European Conference on Mixing, Würzburg, p. 549. BHRA, Bedford.

Fleury, P.-A, Meyer, T. and Renken, A., 1992, Solution polymerization of methyl-methacrylate at high conversion in a recycle tubular reactor. Chem. Engng Sci. 47, 25972602.
Hui, A. W. and Hamielec, A. E., 1972, Thermal polymerization of styrene at high conversions and temperatures. An experimental study. J. Appl. Polym. Sci. 16, 749-769.

Meyer, T. and Renken, A., 1990, Characterization of segregation in a tubular polymerization reactor by a new chemical method. Chem. Eng. Sci. 45(8), 2793-2800.

Nguyen, K. T., Flaschel, E. and Renken, A., 1985, Bulk polymerization of styrenc in a static mixer. Chem. Eng. Comm. 36, 25I-267.

Rempp, P. and Merrill, E. W., 1986, Polymer Synthesis. Hüthig \& Wepf, Heidelberg.

Trivedi, B. C. und Culbertson, B. M., 1982, Maleic Anhydride. Plenum Press, New York.

Warnecke, H. J., Prüss, J. and Langemann, H., 1985, On a mathematical model for loop reactors, I and II. Chem. Engng Sci. 40, 2321-2331. 